\title{
NUMERICAL MODELING OF WAVE PENETRATION IN OSTEND HARBOUR
}

\author{
Vasiliki Stratigaki ${ }^{1}$, Dieter Vanneste ${ }^{1}$, Peter Troch $^{1}$, Stefaan Gysens ${ }^{2}$ and Marc Willems ${ }^{3}$
}

The initial Ostend harbour entrance at the North Sea coast of Belgium is being modified and extended with two new rubble-mound breakwaters. Through an integrated study of the wave penetration in Ostend harbour, the waves are being acquired by prototype measurements and physical and numerical modelling is carried out. Two numerical models are used. SimWave is a numerical model based on Nwogu's extended Boussinesq equations. The second numerical model is MILDwave, a mild-slope wave propagation model based on the equations of Radder and Dingemans. The present study concentrates on applications of the numerical models, throughout the different design stages and construction phases of the new breakwaters.

Keywords: rubble-mound breakwater; wave penetration in harbour; wave propagation model; numerical modeling; Boussinesq model; mild-slope model; MILDwave

\section{INTRODUCTION}

\section{The harbour of Ostend}

The harbour of Ostend, which is situated at the North Sea coast of Belgium, gathers activities related to handling of goods and passengers, but also fishing, yachting and recreation activities. Moreover, the city of Ostend, which is the only one along the Belgian coastline, concentrates lots of visitors, tourists and travelers on a daily basis.

Increasing safety comes, therefore, at the first place for the harbour of Ostend. The city centre lies approximately $4.0 \mathrm{~m}$ bellow water level, while the beach, the sea dike and the quay walls of the inner harbour are not sufficient for its protection against flooding. Figure 1 illustrates the risk the city centre was facing, showing that the waves were easily reaching the sea dike even for wave conditions which were not extreme.

Another problem was related to ship navigation. The initial direction of the navigation channel (Fig. 2, top), combined with difficult wave conditions, created difficulties as the ships were trying to enter the inner harbour (Fig. 2, bottom). Moreover, increasing handling activities demanded the accessibility of larger ships.

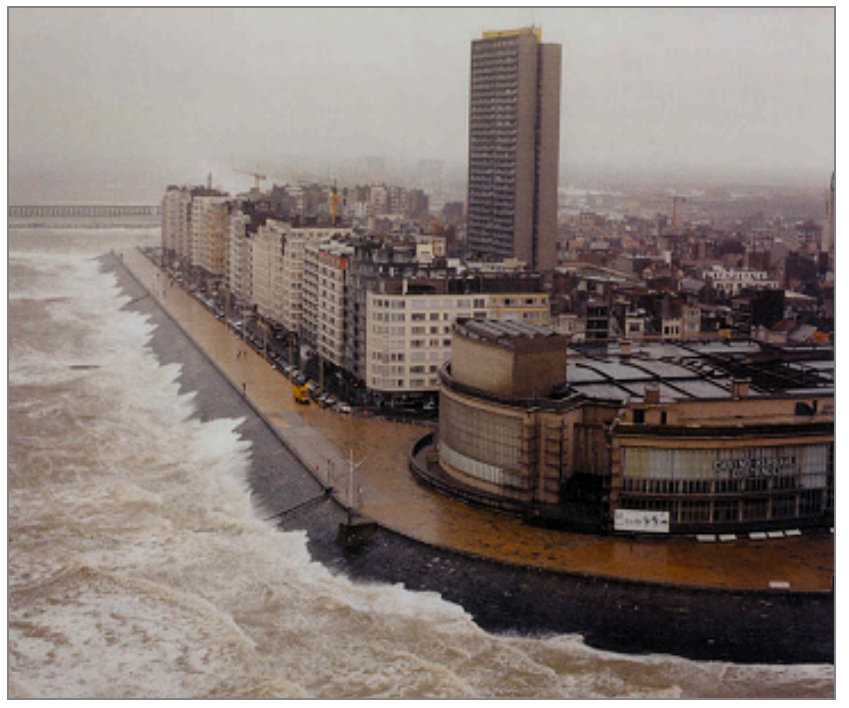

Figure 1. Waves reaching the sea dike and approaching the city centre.

\footnotetext{
${ }^{1}$ Department of Civil Engineering, Ghent University, Technologiepark 904, Zwijnaarde, B-9052, Belgium

${ }_{2}^{2}$ Agency for Maritime and Coastal Services (MDK), Coastal Division, Vrijhavenstraat 3, 8400 Oostende, Belgium

${ }^{3}$ Flemish Authorities, Flanders Hydraulics Research, Berchemlei 115, 2140 Antwerpen, Belgium
} 

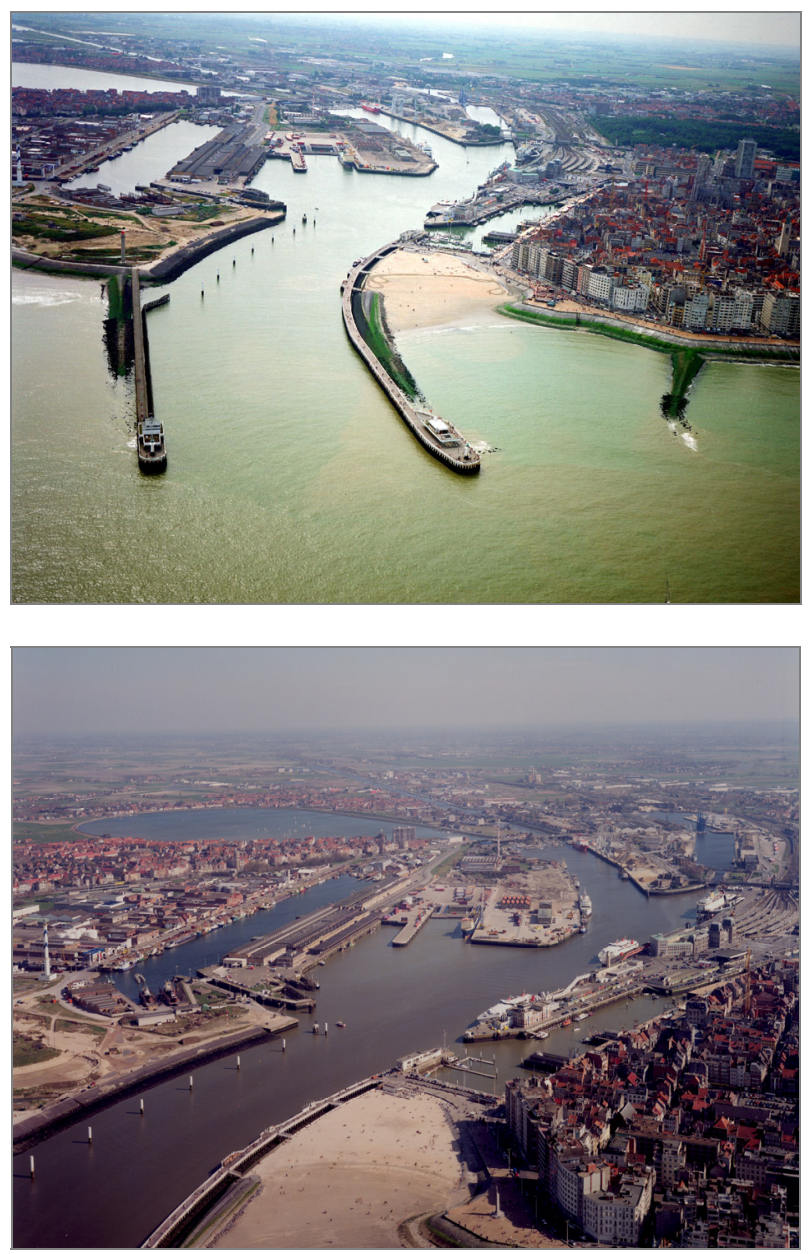

Figure 2. Harbour of Ostend and city center: (top) initial entrance of the harbour, (bottom) inner harbour.

\section{Wave propagation in the harbour of Ostend - An integrated approach}

Therefore, safety and economical reasons lead to a plan of extension and modification of the initial entrance of the Ostend harbour with two new rubble-mound breakwaters. The design of the breakwater lay-out depends on navigation requirements and lower wave penetration into the inner harbour. For the flood risk assessment of the adjacent and low lying city centre, the water level during storm conditions has to be analysed. Moreover, long waves inside the inner harbour may cause unwanted ship agitation.

Three harbour configurations are generally considered, which are presented in Figure 3 by means of bathymetry contour plots: the initial configuration (Fig. 3.a), before the beginning of the project, an intermediate geometry (Fig. 3.b), which is attributed to temporary measures that had to be taken for the harbour, and the final configuration (Fig. 3.c) with two new rubble-mound breakwaters, which is the future completed lay-out of the harbour.

Therefore, three situations are investigated throughout the various studies concerning the harbour:

1. "Initial" situation of the harbour (Fig. 3.a). The entrance of the harbour is situated between two open piers, with a groin underneath both of them, which protrude into the sea and form the access channel.

2. "Intermediate" geometry with preserved western jetty and a new temporary low-crested eastern breakwater (Fig. 3.b), constructed up to $+3.0 \mathrm{~m}$. The eastern jetty is removed and the new navigation channel is almost completed.

3. "Final" geometry (Fig. 3.c) with two new breakwaters, of $650 \mathrm{~m}$ length, each. The eastern breakwater will be an extension of the temporary low-crested breakwater of the "intermediate" situation. The future situation includes also new beaches at the West and East of the breakwaters (beach nourishment) for protection of the city centre against flooding and a new navigation channel, deepened and turned to the East. 

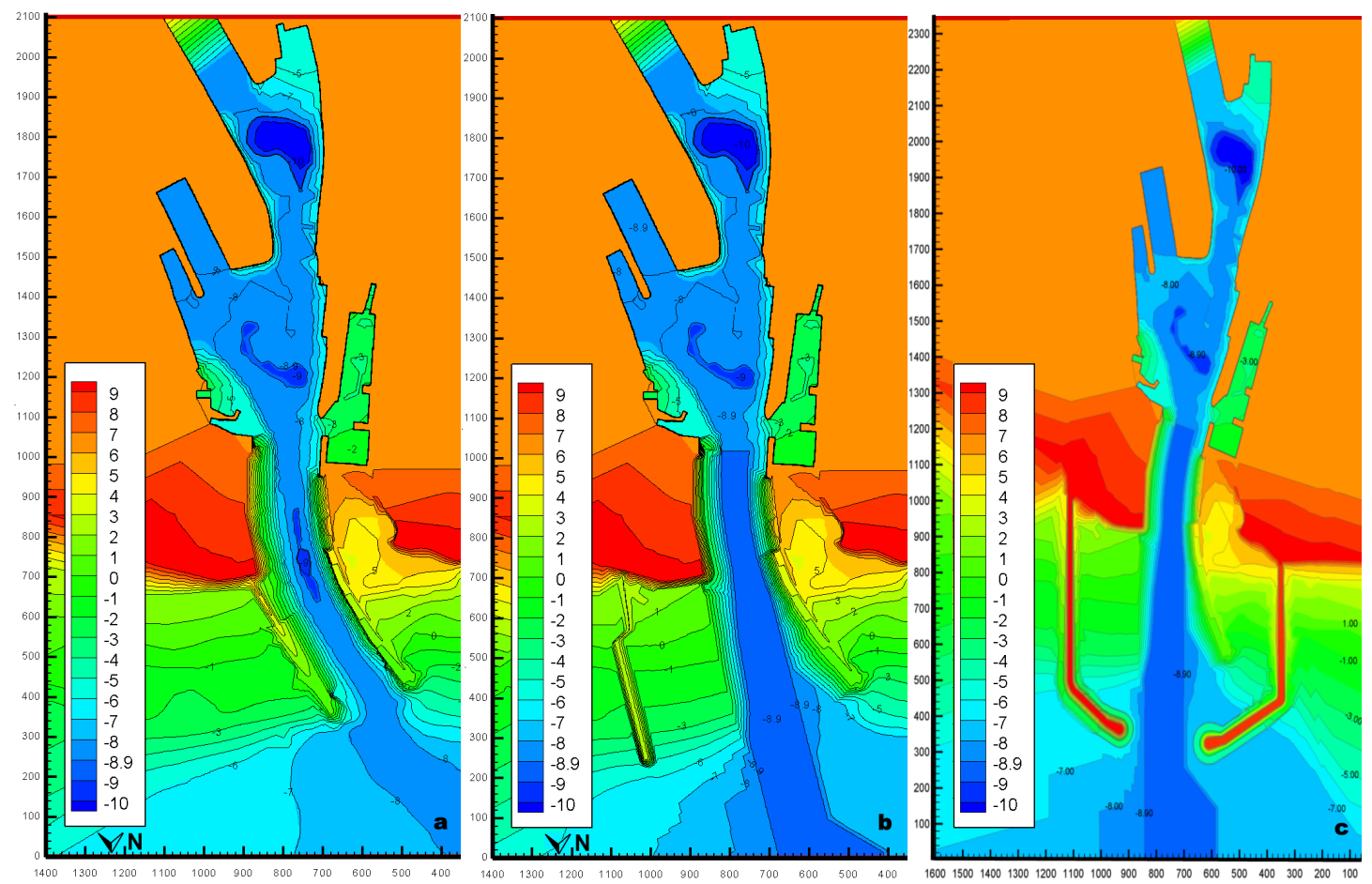

Figure 3. Geometry and bathymetry (levels in TAW*) of: (a) initial situation, (b) intermediate situation and (c) final situation (plot (a) and (b): Cherlet et al. 2005; plot (c): Desnerck et al. 2006).

In the frame of an integrated study for the wave penetration in the harbour of Ostend, the waves are being acquired through prototype measurements, by Ghent University (Belgium), and physical modeling is carried out by Flanders Hydraulics Research (Belgium). Moreover, numerical modeling is carried out by Ghent University. The present study concentrates on the various applications of the numerical modeling, throughout the different design stages and construction phases, leading gradually to the final layout of the harbour of Ostend.

\section{PROTOTYPE MEASUREMENTS AND PHYSICAL MODELING}

\section{Acquisition of waves through field measurements}

For the acquisition of field data, seven wave gauges have been placed in the inner harbour (Fig. 4). Two wave rider buoys, east and west of the harbour entrance (approx. $800 \mathrm{~m}$ off the coast) measure the incident wave climate. All wave gauges (DRUCK pressure sensors) have battery power supply and dedicated signal conditioning and data-acquisition for stand-alone use. The sensors are placed approximately $2.0 \mathrm{~m}$ below low water level. Pressure is converted to surface elevations. Short and long waves and storm set-up (difference between predicted astronomic tide and actual water level) are derived, as well as 15 min wave spectra. Up to now a data-set of four years has been collected.

The calibration of the models (physical and numerical) is based on the storms which occurred during the initial and the intermediate harbour situation.

\section{Physical modeling}

Physical model tests (3D; scale 1:100) are carried out to study the three different harbour situations (initial, intermediate and final). Wave gauges at the seven validation locations, where the waves are being acquired through field measurements, are also included in the physical model, e.g. the wave gauge which appears almost in the middle in Fig. 5 is placed at the 'location 3' shown in Fig. 4.

* TAW ('Tweede Algemene Waterpassing') is the reference water level by which the level measurements are expressed in Belgium. A 'TAW' level of $0.0 \mathrm{~m}$ is equal to the average sea level during low-water conditions in Ostend. 


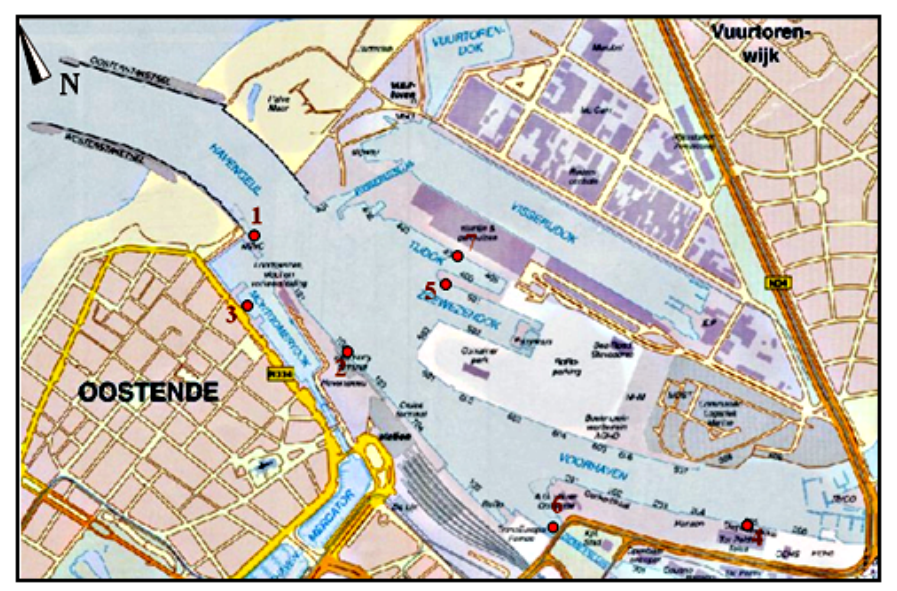

Figure 4. Locations of the seven wave gauges placed in the inner harbour of Ostend (points 1-7).

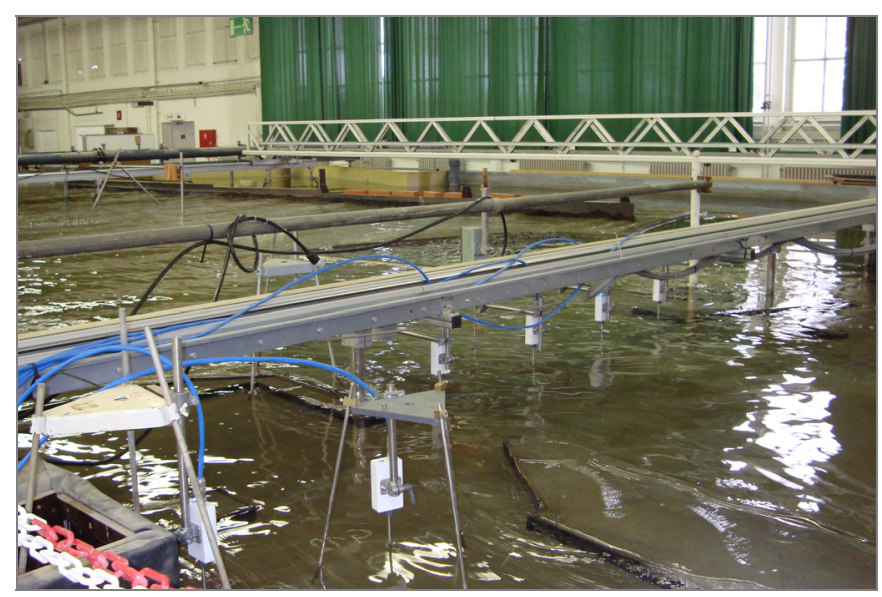

Figure 5. View of the experimental set-up in the wave basin at Flanders Hydraulics Research (Belgium).

\section{NUMERICAL MODELING}

\section{Application methodology of the numerical models}

Two numerical models have been validated and are being used for the studies of the harbour. SimWave, a Boussinesq model and MILDwave, a mild-slope wave propagation model, which are described in the following sections.

The numerical results in the inner harbour are validated using the wave data acquired during the field measurement campaign (see Fig. 4). Therefore, runs using hydraulic conditions with return period 1 year $(\mathrm{RP}=1 \mathrm{yr})$ simulate the operational conditions and are used for the validation with field data. Runs with higher storm return period provide the risk of overtopping over the quay walls in the inner harbour. Regarding the applied hydraulic boundary conditions, the most critical wave directions and wave/storm characteristics are simulated.

For the evaluation of the results of the numerical simulations a common method is followed. The results are presented in terms of significant wave heights $\left(\mathrm{H}_{\mathrm{s}}\right)$ and a disturbance coefficient $\left(\mathrm{k}_{\mathrm{d}}\right)$ for the calculation domain. This coefficient is given by the ratio $\mathrm{H}_{\mathrm{s}} / \mathrm{H}_{\mathrm{sGB}}$, where $\mathrm{H}_{\mathrm{s}}$ is the local significant wave height and $\mathrm{H}_{\mathrm{SGB}}$ is the wave height at the wave generation boundary.

Throughout the different design stages and construction phases, numerical results have been used for various purposes, according to the needs of the evolving harbour layout. In this respect different wave conditions and return periods have been investigated numerically. Return period of 1 year focuses on short term results and corresponds to daily wave conditions, which are more important for the initial and intermediate geometry and bathymetry of the harbour and during the construction phases. Return period of 100 years focuses, on the other hand, on the design criteria of the final configuration of the harbour, while return period of 1000 years concentrates on the investigation of 
wave transmission in the final situation and the risk of flooding over the quay walls in the inner harbour.

Other numerical studies provide wave conditions at particular port locations which become of great interest due to a dynamic situation within the harbour, caused by bathymetry and geometry changes. Numerical modeling is also used for the investigation of the most critical wave direction in terms of wave penetration in the outer and the inner harbour for each of the construction phases. For the validation of the numerical models, measurements taken during prototype storms have been used.

Moreover, input for the armour stability calculations of the two breakwaters has been provided by the numerical models. The most important directions for the wave penetration have been recognised, which were used for estimating the loads of the slopes of the new breakwaters. Modifications with regard to the port bathymetry and geometry are numerically examined, i.e. changes in the bed level, the width or the direction of the access navigation channel, removal of the eastern jetty, submerged or emerged breakwaters according to each of the construction phases. Also, diffraction calculations at particular locations in the inner harbour have been carried out for the determination of their final geometry.

In general, numerical wave gages are used by the numerical models, which provide water surface time series at certain locations of the computational domain. In addition, numerical wave gauges are placed at the same locations as in the field, which allows the validation of the numerical results in the inner harbour by the wave data acquired in the field measurement campaign. In Fig. 6, typical locations of waves gauges used by the numerical models are presented. The seven wave gauges of Fig. 4 are included, which are found in the field, as well as wave gauges of the physical model and, also, locations which are of great interest with regard to wave penetration in the harbour.

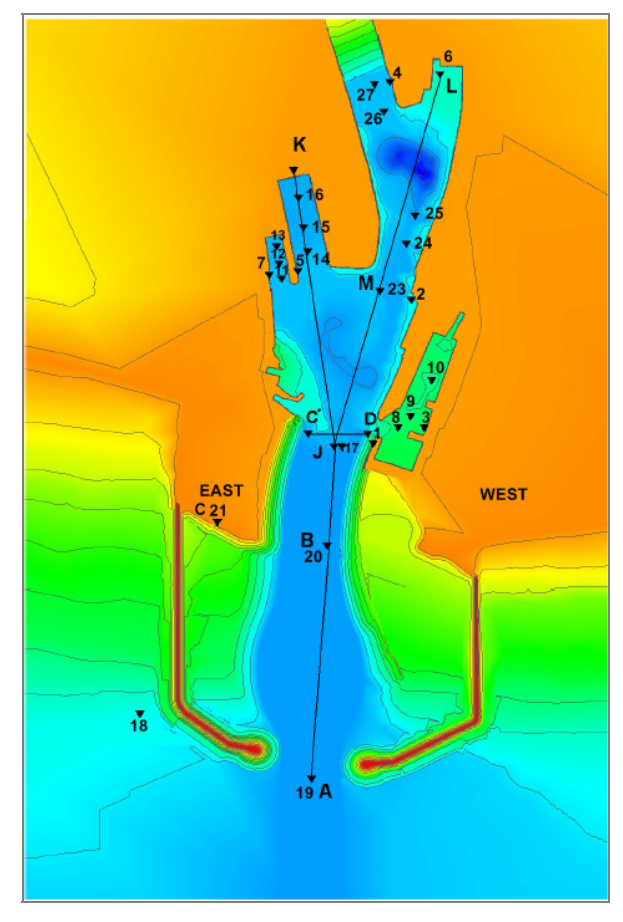

Figure 6. Locations of wave gauges and longitudinal sections AJK and AJL, which are used during numerical modeling (Stratigaki and Troch 2010a).

\section{Numerical modeling with the model SimWave}

SimWave (Sinha et al. 1998) is a numerical model based on Nwogu's (1993) extended Boussinesq model equations, which are solved in the time domain. Wave propagation and transformation are simulated, including shallow water effects (e.g. shoaling, refraction, diffraction, wave run-up and breaking).

This Boussinesq model, is a phase-resolving model and has been applied to study regular and irregular waves propagating over variable water depths, providing instantaneous surface elevations 
$\eta(x, y, t)$ at a reference depth. In Figure 7, typical results showing instantaneous surface elevations for irregular waves are presented, for the initial, the intermediate and the final situation of the harbour.

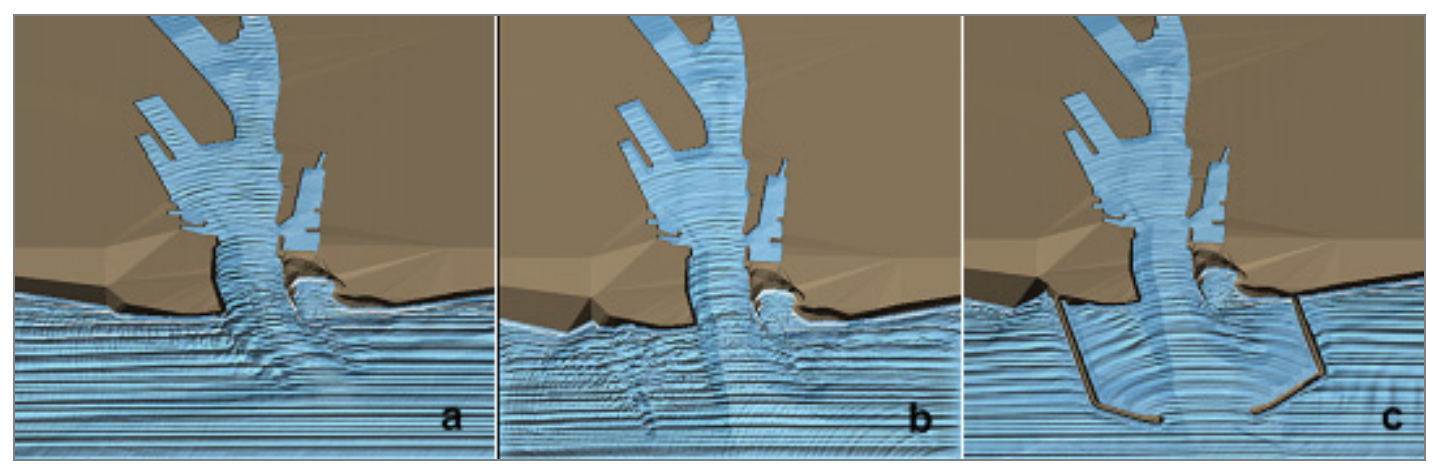

Figure 7. Instantaneous surface elevations in SimWave for the three different configurations of the harbour of Ostend: (a) initial, (b) intermediate and (c) final configuration.

SimWave has been applied for various purposes within the project of the extension of the harbour of Ostend. Each of the different configurations discussed previously and their variants have been studied using SimWave (e.g. in Geeraerts et al. 2002, Cherlet et al. 2005, Stratigaki and Troch 2009b, etc.).

Though SimWave seems to provide accurate results, as they show, in general, good agreement with the field measurements and with the results provided by the linear wave propagation model MILDwave, it is not a problem-free computational tool with regard to convenience of use. As most of the Boussinesq solvers, SimWave suffers from computational instabilities, often causing the simulations to 'crash', while its code cannot be modified by the user. Due to performance limitations of the numerical engine, all numerical simulations were run with $\mathrm{H}_{\mathrm{s}}=1.0 \mathrm{~m}$, independently from the occurring wave height. However, results from numerical simulations have shown that the disturbance coefficient $\left(\mathrm{k}_{\mathrm{d}}\right)$ differs very little if calculated for different absolute $\mathrm{H}_{\mathrm{s}}$ values, when no wave breaking occurs. Moreover, since the required computational time for each simulation in SimWave is high, the resolution of the grids was reduced to $2.0 \mathrm{~m}$ grid cell size.

\section{Numerical modeling with the model MILDwave}

The second numerical model is MILDwave, a mild-slope wave propagation model based on the equations of Radder and Dingemans (1985) and developed by Troch (1998). The phase-resolving model MILDwave is able to generate linear water waves over a mildly varying bathymetry and to calculate instantaneous surface elevations throughout the domain. Wave transformation processes such as refraction, shoaling, reflection, transmission, diffraction and wave breaking can be simulated intrinsically. MILDwave can generate regular and irregular long- and short-crested waves, as well as radiated waves. In Figure 8, a typical result of instantaneous surface elevations in MILDwave is presented, for the final configuration of the harbour.

Typical applications of the model are the study of wave penetration in harbours, e.g. Zeebrugge and Ostend in Belgium (e.g. Vanneste et al. 2008; Stratigaki and Troch 2010b), the harbour of Hanstholm in Denmark (Margheritini et al. 2010) etc., the behaviour of wave energy converters (e.g. Beels et al. 2010a, 2010b; Troch et al. 2010), wave transformation studies, e.g. in the Norwegian coast (Kofoed et al. 2008) and in the Belgian coast for the Thorntonbank, etc. Regarding the harbour of Ostend, MILDwave has been used as a control tool for SimWave, e.g. in studies of diffraction through the gap of the two new breakwaters of the final configuration of the harbour, diffraction through the entrance of particular locations of the inner harbour, e.g. at a location known as 'Montgomery dock', etc.

MILDwave is used and developed as a research tool within the research team of Ghent University. This offers the possibility to modify its code when necessary and extract the desired type of results, or even take into account the required physical phenomena, providing the ability to approach each of the studied cases or problems, separately, 'case-by-case'. With regard to its convenience of use MILDwave has proven to be an easy tool for every user, providing full control and overview of the solver during the simulation. In addition, comparing with results from the Boussinesq solver, a good agreement between the two numerical models can be seen, confirming the good quality of the results of 
MILDwave. Bathymetries can be modelled accurately in MILDwave, since the model has mostly been applied for grid cell sizes of $1.0 \mathrm{~m}$. Finally, MILDwave is able to provide results in a time efficient way, even for large fine grids.

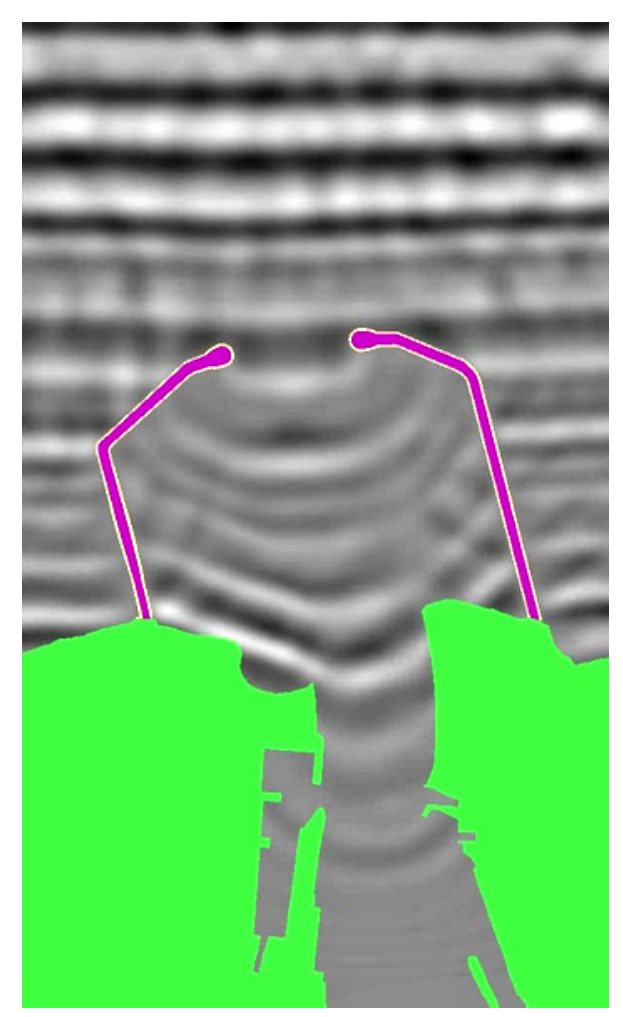

Figure 8. Instantaneous surface elevations in MILDwave of waves propagating and penetrating the harbour, for the final configuration of the new breakwaters.

\section{Using both numerical models, SimWave and MILDwave}

Some physical processes, typical of coastal zones, modify the wave field, depending on local conditions. In various cases throughout this long study of the new harbour of Ostend the two numerical models described previously have been used comparatively, as control tools for each other. Measurements of the significant wave heights at the same locations have been, therefore, used to compare the predictions of the two models. Also, the effectiveness of their use has been investigated with regard to factors such as accuracy, restrictions, numerical instabilities, applicability and time efficiency.

\section{RESULTS OF NUMERICAL MODELING}

A series of simulations concern the initial situation, the present configuration of the harbour, as well as the latest design modifications on the final situation. In this section, indicative numerical results, produced throughout various studies of the harbour of Ostend, are presented. The results refer mainly to the studies carried out the last years.

\section{Results by using the numerical model SimWave}

Figure 9 shows a validation of numerical and physical model results at several locations of the inner harbour, using prototype data. Results for four locations of the inner harbour (see Fig. 4) are presented. The $k_{d}$ values of the model results (physical model and SimWave) are plotted against $k_{d}$ values of field data (indicated as " $k_{d}$ proto" on the horizontal axis of the graphs), which are derived from measurements of prototype storms. The numerical results show very good agreement with field data for all locations. However, the physical model results show significant scatter at the entrance of the inner harbour (location NSYC, "North Sea Yacht Club" denoted as "1" in Fig. 4), despite careful match of hydraulic and boundary conditions. 

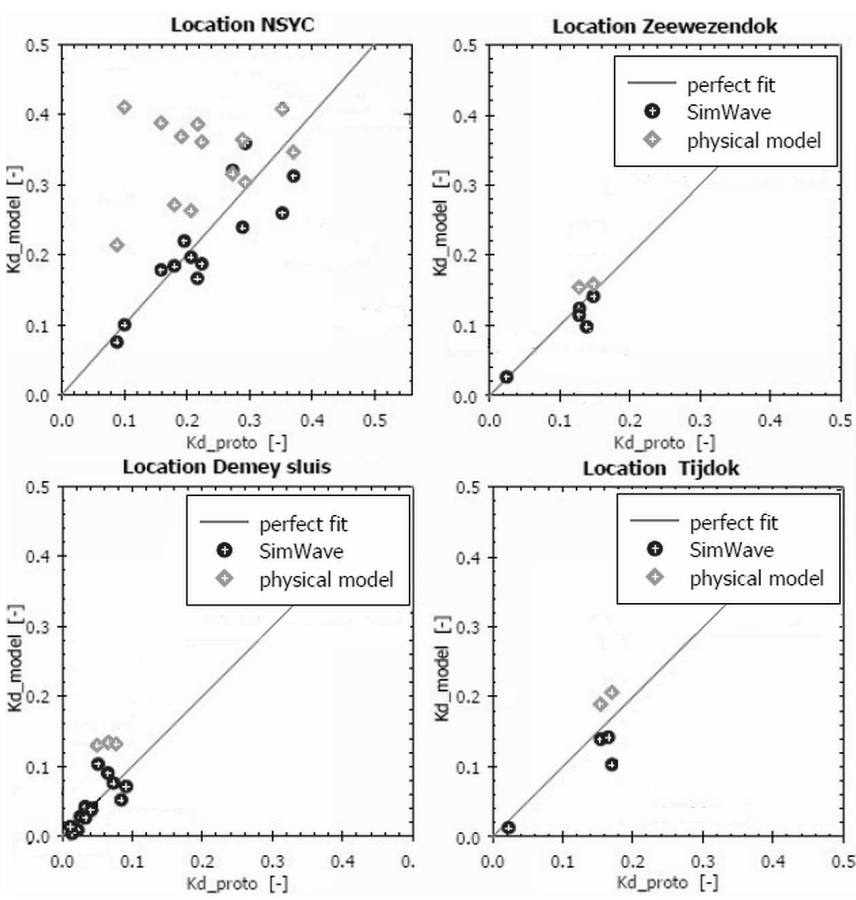

Figure 9. Validation of model results at several port locations using prototype data (Troch and Vanneste 2006).

In Figure 10 a contour plot of $\mathrm{k}_{\mathrm{d}}$ values is presented, for the initial geometry of the harbour, before the beginning of the project. For the initial lay-out of the harbour a return period of 1 year is simulated and for a critical wave direction (North) with regard to wave penetration in the harbour. The numerical results show relatively high $\mathrm{k}_{\mathrm{d}}$ values, in the access channel and the inner harbour, even for storms with return period of 1 year.

In Fig. 11 numerical results are presented for a validation carried out using wave height and wave direction measurements during three prototype storms, which occurred on $9^{\text {th }}$ November $2007,21^{\text {st }}$ March 2008 and $10^{\text {th }}$ February 2009. The bathymetry of the harbour differs, as the storms occurred in different construction (or de-construction) phases, as shown on the graph of Fig. 11. Also, the wave directions are different for each of the storms, as only the critical directions are simulated. In Fig. 11 the evolution of the $\mathrm{k}_{\mathrm{d}}$ values and the bottom levels along the longitudinal section AJL (see Fig. 6) are presented for the three storms. 


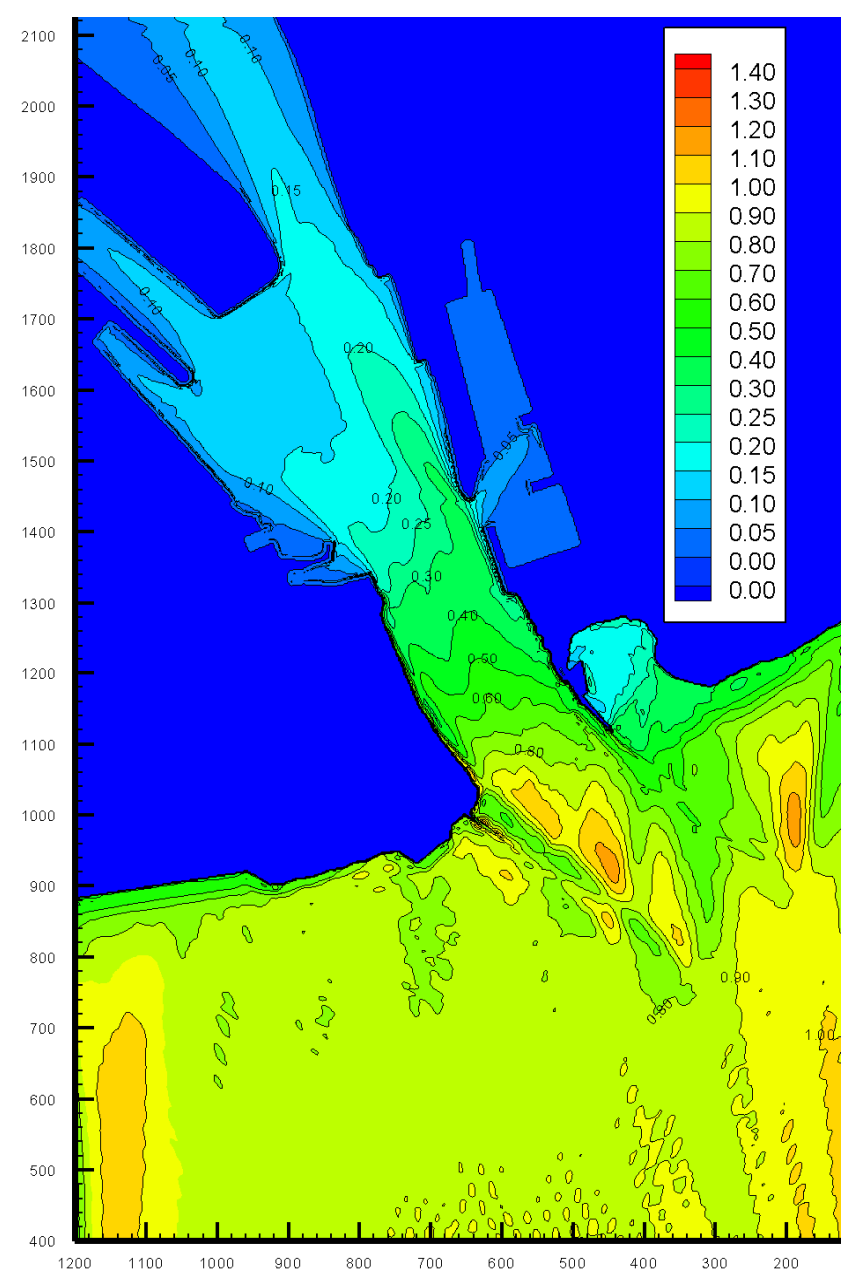

Figure 10. Contour plot of $k_{d}$ values for the initial configuration of the harbour (RP $=1 \mathrm{yr}$, North direction) (Cherlet et al. 2005).

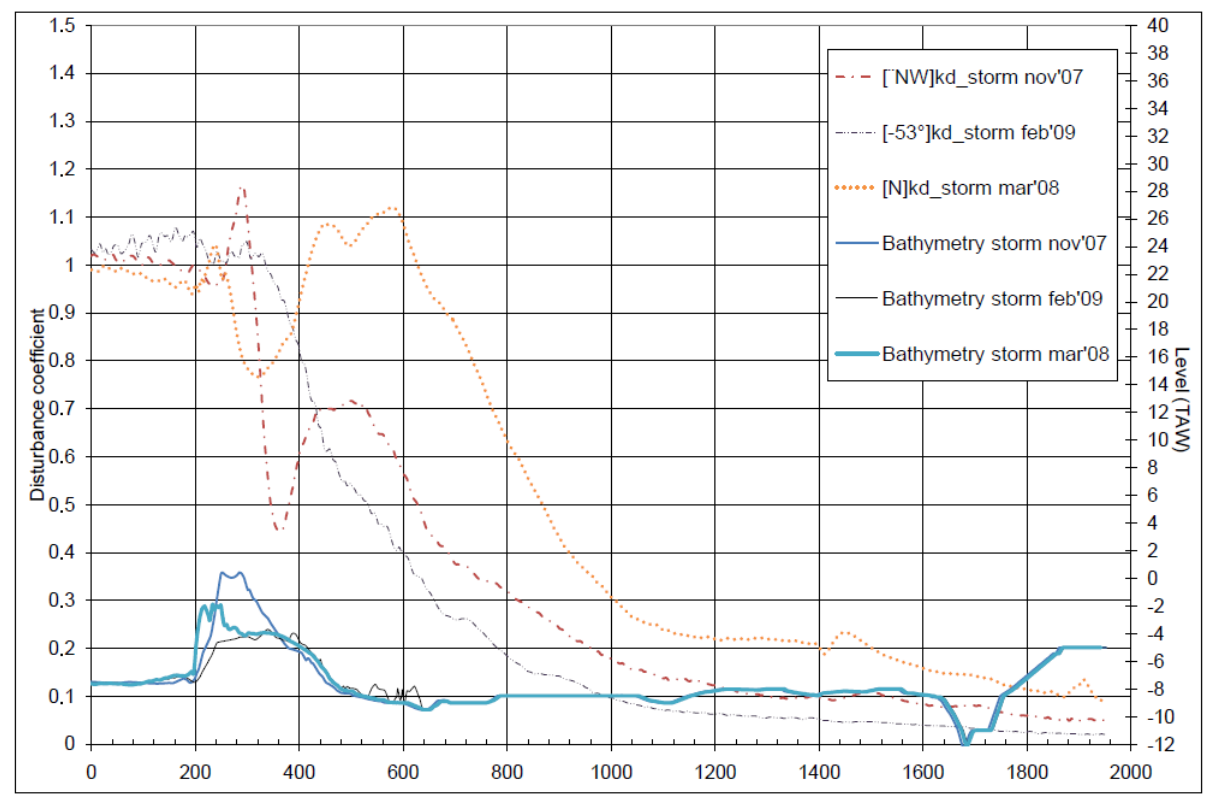

Figure 11. $k_{d}$ values and bottom levels along the longitudinal section AJL (see Fig. 6) for the storms of $9^{\text {th }}$ November 2007, 21 $1^{\text {st }}$ March 2008 and $10^{\text {th }}$ February 2009 (Stratigaki and Troch 2009a). 


\section{Results by using the numerical model MILDwave}

MILDwave has been generally used in combination with SimWave, which is discussed in the following section. Recently, this wave propagation model has been used to study the wave diffraction through a gap located in the inner harbour, known as entrance of Montgomery dock, targeting the reduction of the wave penetration into this part of the harbour.

This location of the inner harbour (Fig. 12, right) suffers from high wave penetration, which creates difficult conditions. Therefore, various configurations of this gap have been studied, in order to find the geometry which offers not only lower $\mathrm{k}_{\mathrm{d}}$ values in Montgomery dock, but also a solution serving architectural and urban purposes.

A similar analysis has been carried out using eight different layouts compared to the initial situation (Troch 2007), aimed at supporting the physical model study and the selection of the best configurations for wave conditions of RP $=100 \mathrm{yrs}$. The recent study (Stratigaki and Troch 2010b) includes thirty four new configurations according to the present needs of the Ostend harbour, using the most critical wave conditions for RP $=1000$ yrs. It is assumed that the long wave behaviour inside Montgomery dock (resulting from the highly reflecting quay walls and rectangular dock layout in plan view) will not be affected substantially by changing gap geometry, and therefore the long wave behaviour will be identical for all tested configurations, and does not need to be modelled in a qualitative numerical modelling. The numerical model MILDwave is suitable for this analysis.

The performance of the tested configurations is evaluated on the basis of the performance for wave diffraction through the gap of Montgomery dock only. The quay walls exhibit total reflection to the waves, while the quay wall opposite the gap is replaced by a sponge layer which absorbs the waves which are entering Montgomery dock.

This location of the inner harbour with the initial gap configuration (width $46 \mathrm{~m}$ ) is shown in Fig. 12 (left: physical model, right: location 'Montgomery dock' within the inner harbour). In Fig. 13 a contour plot of $\mathrm{k}_{\mathrm{d}}$ values is presented, showing a detail of the original gap configuration. The values of the $\mathrm{k}_{\mathrm{d}}$ coefficient become greater than 0.6 by applying critical wave conditions with return period 1000 years for the original entrance at 'Montgomery dock'. Numerical results, as well as laboratory and field observations have revealed the need to modify the entrance.

In Figure 14, examples of simulated configurations of the entrance at 'Montgomery dock' are presented. Therefore, various types of modifications have been numerically examined starting from the initial configuration of the gap (Fig. 14, left), such as extending or widening the quay walls at the entrance, using structures with different orientations, reducing the opening, etc.
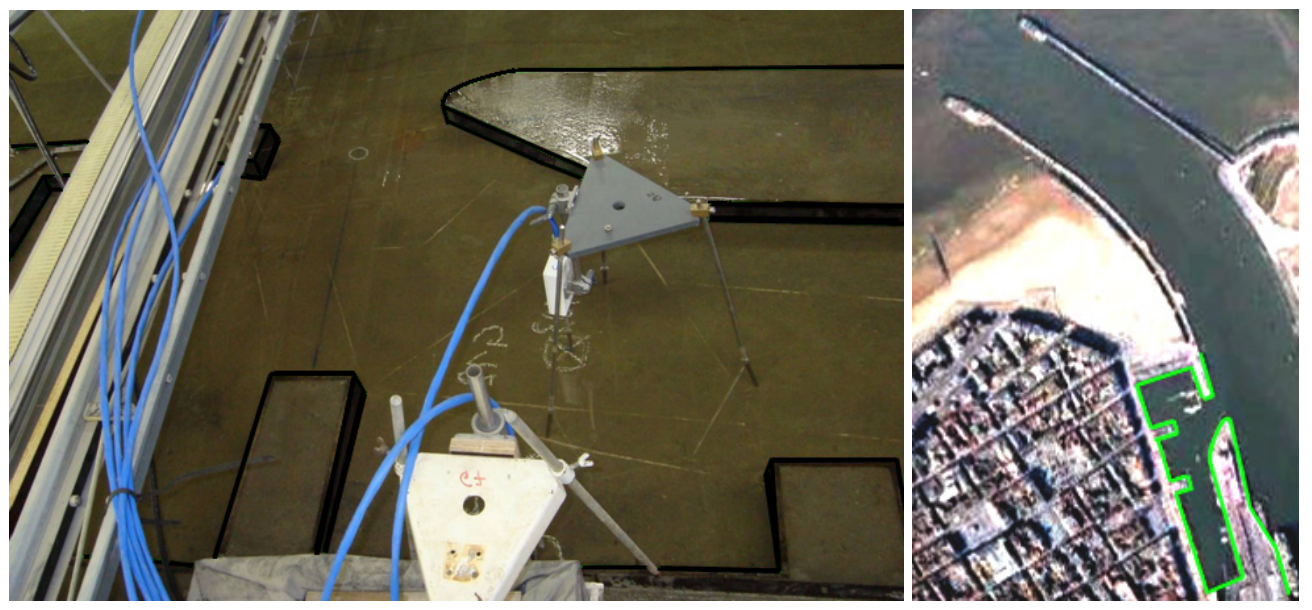

Figure 12. Initial configuration of the entrance at 'Montgomery dock': (left) in the physical model, (right) within the inner harbour. 


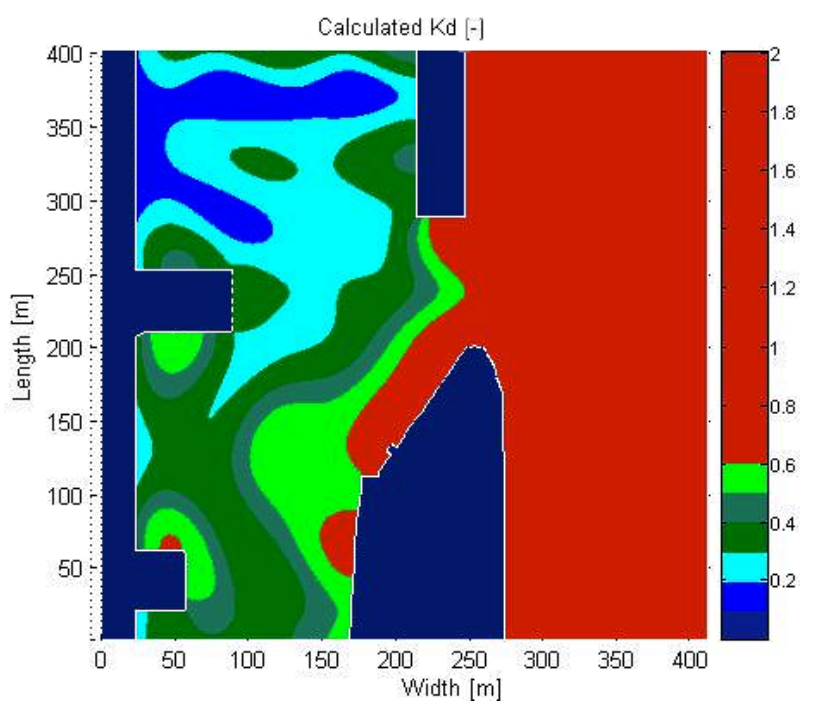

Figure 13. Contour plot of $k_{d}$ values - detail of the initial configuration at the entrance of 'Montgomery dock' (Stratigaki and Troch 2010b).

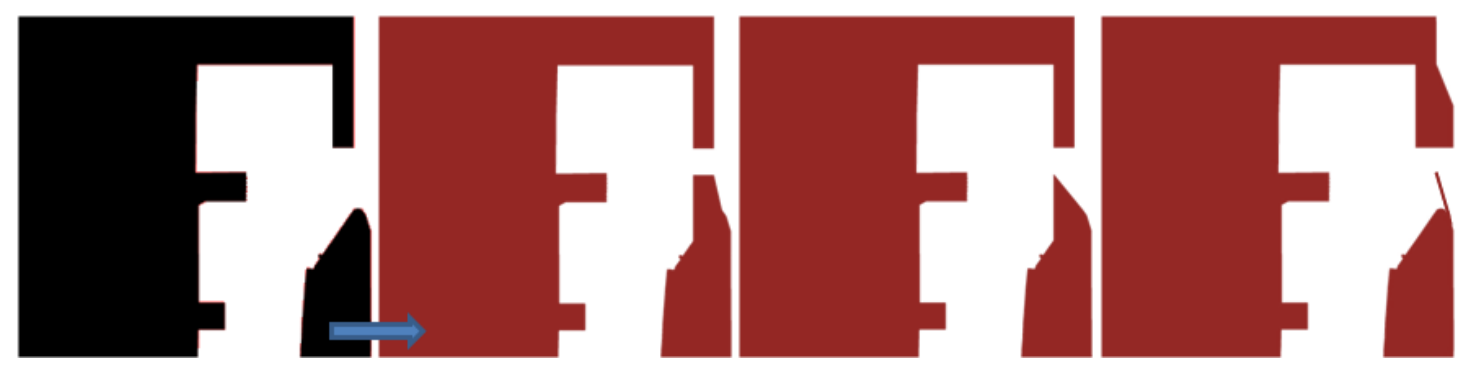

Figure 14. Examples of simulated geometries, starting from the initial gap of $46 \mathrm{~m}$ (left) - details of the entrance at 'Montgomery dock' (Stratigaki and Troch 2010b).

\section{Results by using both numerical models, SimWave and MILDwave}

In certain studies both numerical models have been used, aiming at effective control of the numerical results. Typical cases where SimWave and MILDwave have been used comparatively are wave diffraction studies through the gap of the new breakwaters in the final configuration of the harbour, where wave non linearities are less significant. Numerical simulations have shown that the disturbance coefficient $\left(k_{d}\right)$ differs very little if calculated for different absolute $H_{s}$ values, when no wave breaking occurs. Therefore, the diffraction pattern is mainly determined by direction of incident waves, $T_{p}$ and water level in the harbour.

In Fig. 15 contour plots of $\mathrm{k}_{\mathrm{d}}$ values for the final configuration of the harbour are presented, with SimWave (Fig. 15, top) and MILDwave (Fig. 15, bottom) results, respectively. The areas of high wave penetration are clearly visible in both models, for North wave direction, critical hydraulic boundary conditions for return period 1000 years and irregular long-crested waves. However, the Boussinesq solver has failed to predict the wave heights in the location 'Montgomery dock' of the inner harbour. Similar contour plots are presented in Fig. 16, for NNW wave direction, showing similar patterns regarding wave penetration in the harbour.

The same conclusions can be drawn by observing Fig. 17, where a longitudinal section (N5-N2) of the outer harbour, as shown in the detail of Fig. 17, is presented. The evolution of the bottom and the $\mathrm{k}_{\mathrm{d}}$ values along this section is depicted, by using both numerical models for critical hydraulic conditions of return period 1000 years (for the critical wave directions, $\mathrm{N}$ and NNW). This longitudinal section is selected after observations of the contour plots of $k_{d}$ values of numerical results (e.g. Fig. 1516), where the areas ("jetties") of concentrated wave energy are exposed. In Fig. 17, the thick black line represents the bottom, the solid lines refer to results from SimWave and the symbol lines to 
MILDwave, for two wave directions. The results show good agreement between the two models, especially for NNW direction.
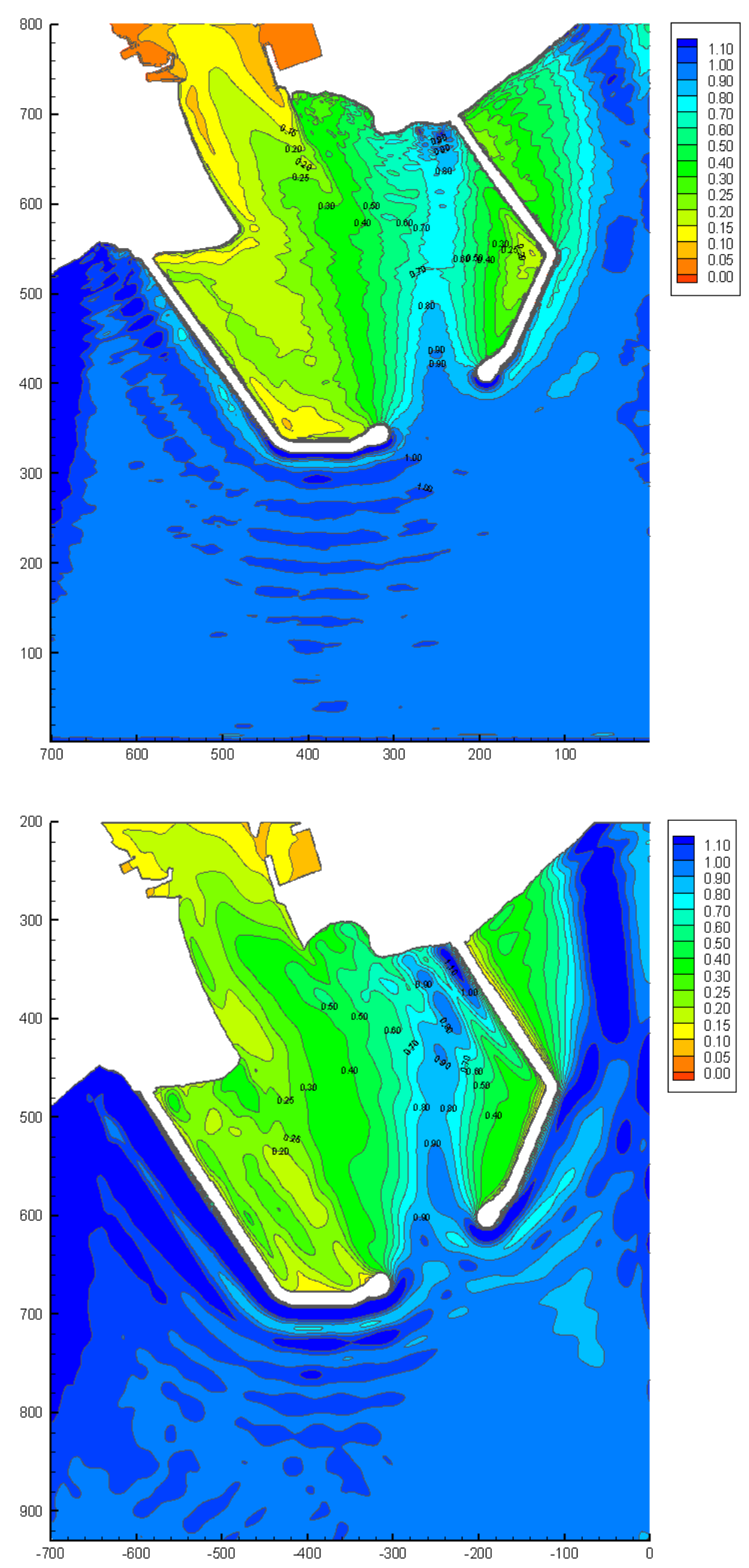

Figure 15. Diffraction through the breakwater gap (RP = $1000 \mathrm{yrs,} \mathrm{North} \mathrm{wave} \mathrm{direction).} \mathrm{Contour} \mathrm{plots} \mathrm{of} k_{d}$ values: (top) SimWave results, (bottom) MILDwave results (Vanneste et al. 2008). 

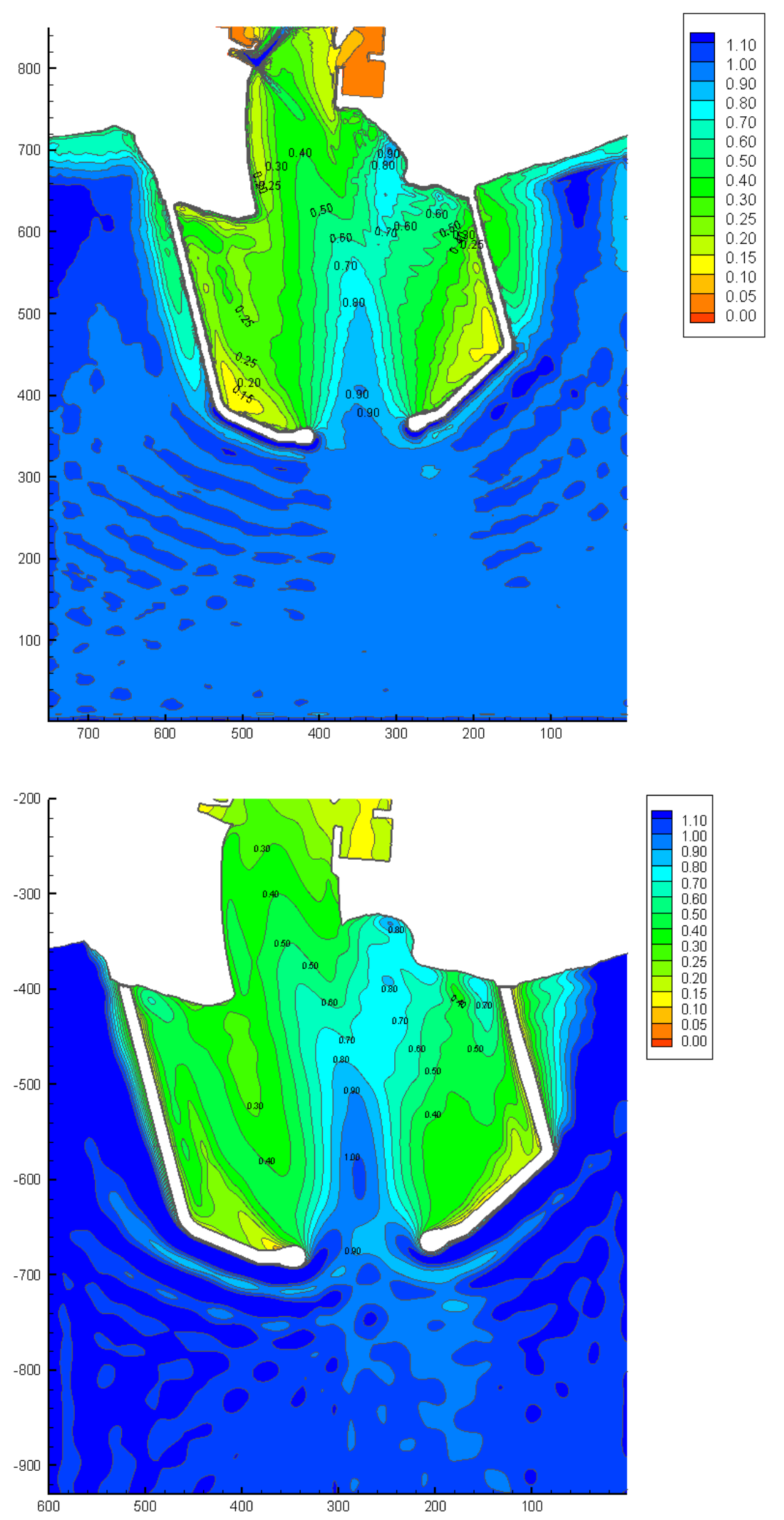

Figure 16. Diffraction through the breakwater gap ( $R P=1000$ yrs, North-NorthWest wave direction). Contour plots of $k_{d}$ values: (top) SimWave results, (bottom) MILDwave results (Vanneste et al. 2008). 


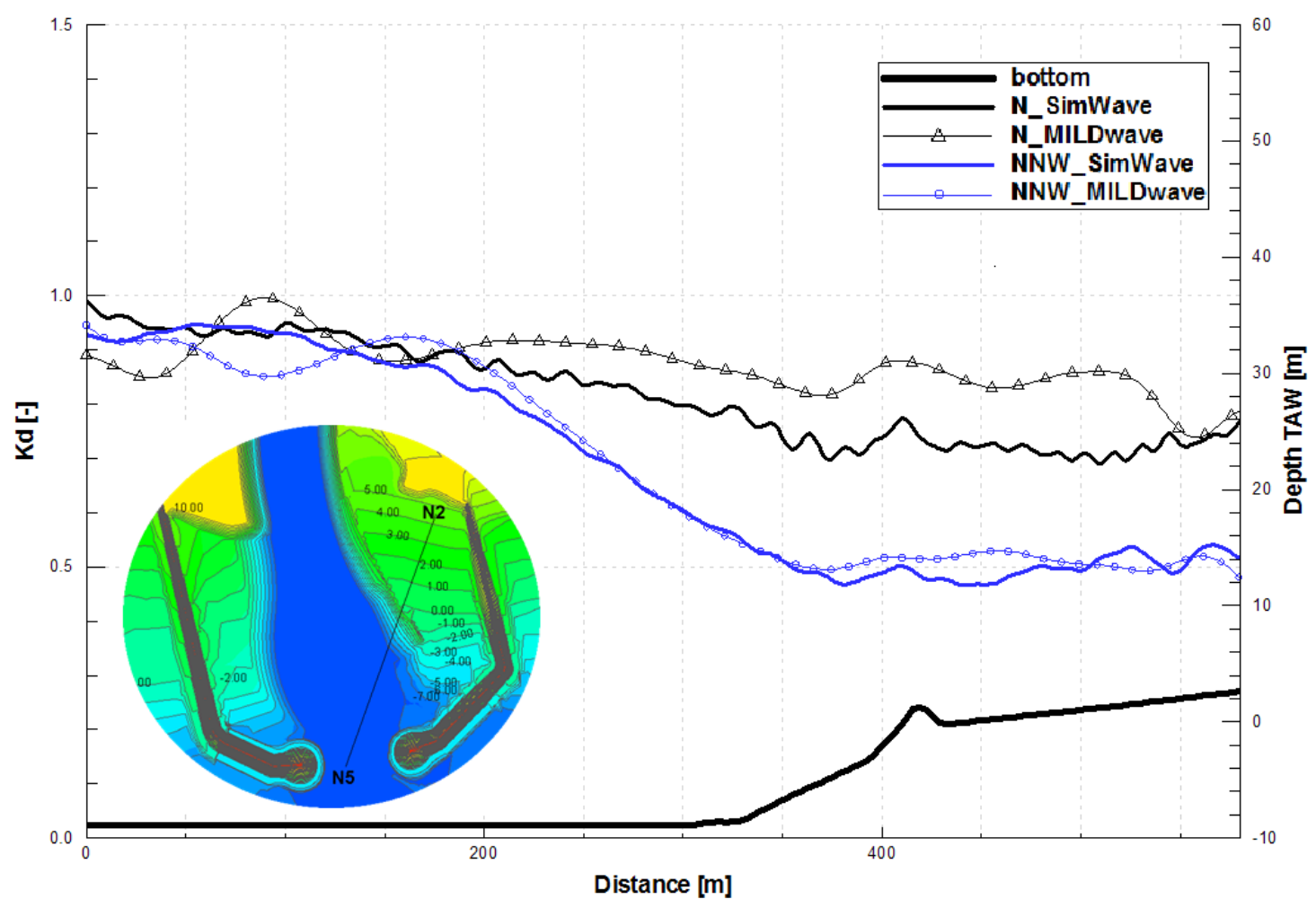

Figure 17. Longitudinal section (N5-N2) of the outer harbour, showing the evolution the $k_{d}$ values and the bottom by using both numerical models for critical hydraulic conditions of return period 1000 years (for $\mathrm{N}$ and NNW wave directions) (Vanneste et al. 2008).

\section{CONCLUSIONS}

Extension and modification works have been planned and are carried out for the harbour of Ostend. Numerical and physical modeling has been applied in order to compare changes in the outer and inner harbour with regard to wave propagation and to estimate the wave heights. Two numerical models have been applied: SimWave (solving Boussinesq equations) and MILDwave (solving mild slope equations).

Validation of the models by prototype storm measurements shows good agreement between field data and model results. The numerical models have been used, in general, for various purposes. SimWave has been mainly applied for the simulation of the initial and the intermediate configuration, providing results important during the construction phases. MILDwave has been used for wave diffraction studies, e.g. through the entrance of 'Montgomery dock' in the inner harbour, providing results for 34 different configurations of this location. Both models have been comparatively used during studies of wave diffraction through the gap of the new breakwaters (final configuration) with results which show good agreement. The results are presented by means of contour plots and cross sections, in terms of a disturbance coefficient $\left(\mathrm{k}_{\mathrm{d}}\right)$ for the calculation domain, allowing easy comparisons between the applied solvers.

\section{ACKNOWLEDGMENTS}

The first author would like to acknowledge her Ph.D. funding grant of the Research Foundation Flanders, Belgium (Fonds voor Wetenschappelijk Onderzoek Vlaanderen, FWO). 


\section{REFERENCES}

Beels, C., P. Troch, G. De Backer, M. Vantorre, and J. De Rouck. 2010a. Numerical implementation and sensitivity analysis of a wave energy converter in a time-dependent mild-slope equation model. Coastal Engineering, 57 (2010).

Beels, C., P. Troch, K. De Visch, J.P. Kofoed, and G. De Backer. 2010b. Application of the timedependent mild-slope equations for the simulation of wake effects in the lee of a farm of Wave Dragon wave energy converters. Renewable Energy Journal, 35 (2010) 1644-1661.

Cherlet, J., P. Troch, G. Herrling, and J. De Rouck. 2005. Design of Oostende harbour: Numerical simulation of wave propagation: comparison of present and near-future situation. DBO107/73. Ghent: Ghent University, Belgium, 64 pp. November 2005.

Desnerck P., P. Troch, and J. De Rouck. 2006. Design of Oostende Harbour: Numerical simulation of wave propagation: comparison of near-future construction phase and several alternative future situations. DBO107/78. September 2006. Ghent: Ghent University, Belgium. 75 pp.

Geeraerts, J., P. Troch, J. De Rouck, and L. Van Damme. 2002. Design of Oostende Harbour: numerical simulation of wave penetration, 30th PIANC Navigation Congress, 22 - 26 September 2002, Sydney (Australia), pp. 9 (CD-ROM).

Kofoed, J.P., L. Margheritini, V. Stratigaki, and P. Troch. 2008. Estimation of Wave Conditions for SSG Breakwater at Svåheia SSG pilot site, Aalborg: Aalborg University. Department of Civil Engineering. 154 pp. (DCE Contract Reports; 52).

Margheritini, L., J.P. Kofoed, V. Stratigaki, and P. Troch. 2010. Estimation of Wave Conditions for SSG Breakwater at Hanstholm Location, Aalborg: Aalborg Universitet. Institut for Byggeri og Anlæg. 78 pp. (DCE Contract Reports; 90).

Nwogu, O.G.. 1993. An alternative form of the Boussinesq equations for the nearshore wave propagation, Journal of Waterway, Port, Coastal and Ocean Engineering, 119(6), pp.618-638.

Radder, A.C., and M.W. Dingemans. 1985. Canonical equations for almost periodic, weakly nonlinear gravity waves, Wave Motion, 7, 473-485.

Sinha, A., and G. Wei. 1998. SimWave, a Boussinesq model wave simulator, program manual, CSM Consulting Inc., Worthington, USA.

Stratigaki, V., and P. Troch. 2009a. Design of Oostende harbour: Numerical simulation of wave propagation - Simwave validation using prototype storms of 09nov2007, 21mar2008 and 10feb2009. DBO107/91. June 2009. Ghent: Ghent University, Belgium. 26 pp.

Stratigaki, V., and P. Troch. 2009b. Design of Ostend harbour, Numerical simulation of wave propagation: SimWave validation using the layout of Construction Phases 1 and 2 of the breakwaters. DBO107/93. August 2009. Ghent: Ghent University, Belgium. 19 pp.

Stratigaki, V., and P. Troch. 2010a. Design of Ostend harbour, Numerical simulation of wave propagation: Wave conditions in the inner port, Locations of Wave gauges, final situation T2. DBO107/98. January 2010. Ghent: Ghent University, Belgium. 20 pp.

Stratigaki, V., and P. Troch. 2010b. Design of Ostend harbour: numerical simulation of wave diffraction through the gap at Montgomery dock using the 'mild slope' wave propagation model, MILDwave. March 2010. Flemish Government, Brussels, Belgium.

Troch, P.. 1998. MILDwave - A numerical model for propagation and transformation of linear water waves, Internal Report, Department of Civil Engineering, Ghent University.

Troch, P., and D. Vanneste. 2006. Design of Oostende harbour: Numerical simulation of wave propagation - Simwave validation using prototype storms. DBO107/81. December 2006. Ghent: Ghent University, Belgium. 26 pp.

Troch, P.. 2007. Design of Oostende harbour: Numerical simulation of wave diffraction through the gap at Montgomery dock. DBO107/030307. March 2007. Ghent: Ghent University, Belgium. 12 pp.

Troch, P., C. Beels, J. De Rouck, and G. De Backer. 2010. Wake effects behind a farm of wave energy converters for irregular long-crested and short-crested waves. $32^{\text {nd }}$ International Conference on Coastal Engineering, Shanghai, China, ASCE, Paper 217.

Vanneste, D., V. Stratigaki, and P. Troch. 2008. Design of Oostende Harbour: Numerical simulation of wave propagation - Wave conditions at Zeeheldenplein. DBO107/86. December 2008. Ghent: Ghent University, Belgium. 37 pp. 